\title{
Composição florística e estrutura da comunidade vegetal em diferentes fitofisionomias do Pantanal de Poconé, Mato Grosso
}

\author{
Floristic composition and structure of the plant community of different \\ phytophysiognomies in the Pantanal of Poconé, Mato Grosso
}

\author{
Rodrigo Ferreira de Morais ${ }^{1,3}$, Edna Cavalcante Saraiva da Silva ${ }^{2}$, Mariana Regina Lema Metelo ${ }^{2}$ \\ \& Fernando Ferreira de Morais ${ }^{1}$
}

\begin{abstract}
Resumo
Esta pesquisa teve como objetivo analisar a composição e estrutura de comunidade vegetal de quatro fitofisionomias no Pantanal de Poconé, estado de Mato Grosso, partindo do pressuposto de que cada grupo de amostras constitui um tipo de comunidade e haverá um grupo correspondente de espécies que caracterizam a comunidade em particular. Foram implantadas cinco parcelas de $50 \times 50 \mathrm{~m}$ e subdivididas em subparcelas de $10 \times 10 \mathrm{~m}$. Foram considerados na amostragem os indivíduos com CAP (circunferência a altura do peito) $\geq 10 \mathrm{~cm}$. A similaridade florística e estrutural entre as quatro fitofisionomias foram avaliadas pelo método de agrupamento por médias não ponderadas - UPGMA, com uso do coeficiente de Jaccard e Bray-Curtis. Foi utilizada a DCA para ordenação das parcelas e TWINSPAN para análise de espécies indicadoras para as fitofisionomias. Nas quatro fitofisionomias foram amostradas 55 espécies pertencentes a 30 famílias. A UPMGA indicou diferenças florística e estrutural entre cambarazal, floresta semidecidual e cerrado sensu stricto e campo de murundu e similaridade entre as formações semideciduais. A DCA ordenou as fitofisionomias de acordo com o gradiente de inundação e a TWINSPAN indicou a existência de espécies indicadoras para as fitofisionomia.
\end{abstract}

Palavras-chave: pulso de inundação, espécies indicadoras.

\begin{abstract}
The aim of this research was to analyze the composition and structure of the plant community in four phytophysiognomies at Pantanal Poconé-Mato Grosso, assuming that each sample group is a type of community, and there would be a corresponding group of species that characterize that community. We set up five plots of $50 \times 50 \mathrm{~m}$ and subdivided each one into subplots of $10 \times 10 \mathrm{~m}$. In each subplot, individuals with CAP (circunference at breast height) $\geq 10 \mathrm{~cm}$ were sampled. To check the structural and floristic similarity of the five vegetation types the unweighted averages grouping method was used - UPGMA, with Jaccard's coefficient and Bray-Curtis, respectively. DCA ordination of plots was used for inundation gradient analysis and TWINSPAN indicator species groups for the three strata. In the four areas 55 species belonging to 30 families were sampled. The UPMGA indicated floristic and structural differences between "cambarazal", savanna types and "campo de murundu" and similarity between the semideciduous formations. The DCA separated the vegetation types according to the level of flooding and TWINSPAN indicated the existence of typical species for each vegetation type. In the Pantanal, some species may be restricted to certain types of vegetation, and these species can be used as indicators of the effect of flooding and possible changes in flood pulse dynamics in plant communities.
\end{abstract}

Key words: flood pulse, indicator species.

\footnotetext{
${ }^{1}$ Universidade Estadual Paulista Julio de Mesquita Filho, Inst. Biociências, Depto. Botânica, Av 24A, Rio Claro, SP, Brasil.

${ }^{2}$ Cento Universitário UNIVAG, Av. Dom Orlando Chaves n. 2.655, Bairro Cristo Rei, Várzea Grande, MT, Brasil.

${ }^{3}$ Autor para correspondência: morais_rf@yahoo.com.br.
} 


\section{Introdução}

O Pantanal é uma das maiores áreas alagáveis contínuas do planeta, cobrindo aproximadamente $140.000 \mathrm{~km}^{2}$ da Bacia do Alto Rio Paraguai (BAP) e seus tributários, que drenam o Cerrado do Brasil Central (Adámoli 1982). A vegetação é heterogênea e influenciada por quatro biomas: Floresta Amazônica, Cerrado (predominante), Chaco e Floresta Atlântica (Harris et al. 2005).

Esta imensa planície de inundação foi declarada Patrimônio Nacional pela Constituição Brasileira de 1988 e como área úmida de importância internacional pela Conservação Ramsar. Em 2000 foi designada como Reserva da Biosfera pela Unesco (Patrimônio Natural da Humanidade), oferecendo oportunidade única para a conservação da biodiversidade em conjunção com o desenvolvimento sustentável (Harris et al. 2005; Costa et al. 2010).

A inundação é o fenômeno ecológico mais importante que caracteriza o Pantanal e, diferenças na topografia e nas condições hidrológicas podem influenciar nos estratos vegetacionais e a baixa declividade dificulta o escoamento da água, e facilita inundações periódicas e prolongadas (Cunha \& Junk 2001; Silva et al. 2000; Salomão et al. 2008).

Assim, o regime de inundação e tipos de solo pode propiciar a formação de diferentes habitats que são responsáveis pela grande variedade de formações vegetacionais e, consequentemente, pela heterogeneidade da paisagem, que abriga uma riquíssima biota terrestre e aquática (Pott \& Adámoli 1999).

Neste sentido, na fisionomia pantaneira, o pulso de inundação em combinação com o mesorelevo, originam o aparecimento de ambientes característicos, como as cordilheiras (paleodiques), com vegetação arbórea mais densa, ocupando áreas mais elevadas (Silva et al. 2000; Nunes da Cunha \& Junk 2001; Salomão et al. 2008) e as áreas mais baixas, tendendo para campo à medida que aumenta o grau de inundação (Silva et al. 2000; Costa et al. 2010), onde a vegetação dominante estabelecida nesses locais variam de formações de cerradão a campo (Abdon et al. 1998).

No Pantanal, Silva et al. (2000) identificaram 16 classes de vegetação com base nas fitofisionomias, sendo os campos a fisionomia mais representativa (31\%), seguida do cerradão (22\%), cerrado $(14 \%)$, campos inundáveis $(7 \%)$, floresta semidecídua (4\%), mata de galeria $(2,4 \%)$ e tapetes de vegetação flutuantes ou 'baceiros' $(2,4 \%)$.
Na região de Mato Grosso, o Pantanal apresenta diferentes regiões fitogeográficas que se interpenetram, onde as florestas heterogêneas bem estratificadas apresentam maior diversidade e diferenciação de nichos ecológicos além de paisagens que suportam maior diversidade de plantas (Pott \& Pott 1994; Nunes da Cunha \& Junk 1999; Nunes da Cunha \& Junk 2001; Souza \& Souza 2004; Pott \& Pott 2009; Costa et al. 2010).

As diferenças florísticas e fitofisionômicas independem das distâncias que separam as áreas e possivelmente essas diferenças estão relacionadas às variações no solo, da disponibilidade de água no lençol freático, da influência do fogo, da substituição de estágios serais para cerradão ou floresta, dos fatores estocásticos ou relacionados à distribuição das espécies como o pulso de inundação (Borges \& Shepherd 2005).

Abdon et al. (1998) e Pott \& Pott (2009) afirmam que a vegetação é um importante indicador das condições ambientais de uma região, tanto no que se refere à proteção do solo, quanto na definição de habitats de animais silvestres. Neste contexto, estudos da florística e da fitossociologia representam o passo inicial para o conhecimento da comunidade vegetal, pois, associado à sua estrutura e dinâmica pode-se construir uma base teórica que subsidie a conservação dos recursos genéticos, a conservação de áreas similares e a recuperação de áreas ou fragmentos florestais degradados, contribuindo substancialmente para seu manejo (Vilela et al. 1993; Custódio Filho et al. 1994).

Vários trabalhos foram realizados com base na florística e fitossociologia do Pantanal (Cunha 1990; Abdon et al. 1998; Nunes da Cunha \& Junk 1999; Pott \& Adámoli 1999; Silva et al. 2000; Nunes da Cunha \& Junk 2001; Souza \& Souza 2004; Borges \& Shepherd 2005; Costa et al. 2010). Entretanto, existe ainda a necessidade de trabalhos que abordem diferenças na composição florística, estrutura de comunidade e possíveis espécies indicadoras, de grupos ou comunidades em diferentes fitofisionomias, para entendimento da distribuição da riqueza e da heterogeneidade da paisagem no Pantanal.

Esta pesquisa teve como objetivo analisar a composição e estrutura de comunidade vegetal de quatro fitofisionomias no Pantanal de PocnéMT, partindo do pressuposto de que cada grupo de amostras constitui um tipo de comunidade e haverá um grupo correspondente de espécies que caracterizam a comunidade em particular. 


\section{Material e Métodos}

Área de estudo

O Pantanal é uma depressão sazonalmente alagável e situa-se quase inteiramente em território brasileiro, pertencente à bacia do Alto Paraguai, integrante da bacia Platina (Abdon \& Silva 2008). O Pantanal brasileiro está inserido na Região Centro-Oeste onde $35 \%$ de sua área encontra-se no estado de Mato Grosso e $65 \%$ encontra-se no estado de Mato Grosso do Sul (Abdon \& Silva 2008). O Pantanal Mato-Grossense compreende os municípios de Poconé, Santo Antônio do Leverger, Cáceres, Barão de Melgaço e Nossa Senhora do Livramento (Abdon et al. 1998).

O clima da região é do tipo AW de acordo com classificação de Köppen com duas estações bem definidas: a estação seca de maio até setembro e a estação chuvosa, de outubro até abril (Cunha \& Junk 1999). A precipitação máxima é de 1,384 mm no mês de janeiro, com precipitação mínima no mês de julho. A temperatura média anual é de $25,8^{\circ} \mathrm{C}$, enquanto julho é o mais frio. $\mathrm{O}$ processo de inundação sazonal é dividido em quatro fases: enchente e cheia (outubro a abril), vazante e seca (maio a setembro) (Rebellato \& Cunha 2005).

Para seleção das fitofisionomias foram utilizados os critérios (Felfili et al. 2005): tipo de solo, declividade e o tempo de inundação. Assim foram selecionadas: uma área de Formação Savânica (cerrado sensu stricto Ribeiro \& Walter 2008) caracterizada pela ausência de inundação, plantas de menores alturas e diâmetros e presença de Poaceae; duas áreas de Floresta Semidecidual que apresentam tempo de inundação de dois a três meses, formação de sub-bosques e presença de emergentes; uma área de Cambarazal caracterizada por apresentar inundação que persiste durante todo período de enchente com presença de sub-bosques e emergentes e; uma área de campo de murundu que é caracterizada por uma planície de inundação onde se encontram distribuída os murundus, porém não ocorre a inundação dos murundus.

Esta pesquisa foi realizada na Reserva Particular de Patrimônio Natural - RPPN SESC Pantanal certificada pela Portaria do IBAMA n ${ }^{\circ} 071 / 97-\mathrm{N}$,

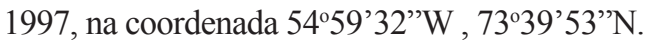

Análise da estrutura da

comunidade vegetal

Para análise da estrutura da comunidade vegetal, foram selecionadas quatro fitofisionomias.
Em cada fitofisionomia foi estabelecida uma parcela de $50 \times 50 \mathrm{~m}$ que foi subdividida em subparcelas de $10 \times 10 \mathrm{~m}$. A coleta e herborização do material botânico seguiu o descrito por Fidalgo \& Bononi (1984). Foram coletadas amostras de material fértil ou vegetativo de todos os indivíduos plaqueados nas cinco parcelas. A identificação foi realizada com auxílio de literatura especializada, consulta a especialista e comparações com a coleção do Herbário da Universidade Federal de Mato Grosso do Sul - UFMS e de Mato Grosso - UFMT.

A nomenclatura utilizada foi a proposta pelo sistema de classificação Angiosperm Phylogeny Group III e revisão de Souza \& Lourenzi (2008). As sinonímias entre espécies foram verificadas nos sites do Missouri Botanical Garden. O material encontra-se depositado no Herbário do UNIVAG Centro Universitário.

Para análise da estrutura da comunidade vegetal foram amostrados e plaqueados os indivíduos contidos nas cinco parcelas com PAP (perímetro à altura do peito a $1,30 \mathrm{~m}$ do solo) $\geq$ $10 \mathrm{~cm}$. Dos indivíduos marcados foram aferidas as seguintes informações: PAP do caule e altura.

\section{Análises dos dados}

Os parâmetros fitossociológicos utilizados foram os descritos por Mueller-Dombois e Ellenberg (1974): densidade, frequência e dominância (relativa), índice de valor de importância e de cobertura. Também foram calculados os índices de diversidade de Shannon (H' nats/ind) e a equabilidade de Pielou (J') (Margurran 1988).

Para verificar a similaridade entre as quatro fitofisionomias utilizou-se o método de agrupamento por médias não ponderadas (UPMGA); para tanto, foi utilizado o coeficiente de Jaccard para confecção do dendrograma de similaridade florística (Felfili et al. 2011) e para abundância o coeficiente de Bray-Curtis (Capelo 2003; Felfili et al. 2011). Utilizou a análise de correspondência distendida-DCA para ordenar as subparcelas com base na matriz de abundância das espécies e verificar a existência de uma tendência de agrupamento em relação ao tempo de inundação. Utilizou-se a Two Way Indicator Species Analysis - TWINSPAN, para análise de espécies indicadoras para cada fitofisionomia, partindo do princípio de que cada grupo de amostras constitui um tipo de comunidade e haverá um grupo correspondente de espécies que caracterizam a comunidade em particular (Capelo 2003; Felfili et al. 2011). 


\section{Resultados e Discussão}

Levando em consideração as quatro fitofisionomias estudadas, foram amostradas 55 espécies pertencentes a 29 famílias botânicas. As famílias mais representativas em número de espécies foram Fabaceae e Myrtaceae (sete espécies), Rubiaceae (seis espécies),
Bignonicaceae e Polygonaceae (três espécies) e as demais famílias apresentaram entre uma e duas espécies (Tab. 1).

Na Figura 1a,b pode-se observar que o Cerrado, Cambarazal e Campo de Murundu apresentam baixa similaridade (Sorensen e Bray-Curtis $<0.50$ ) e as Florestas semideciduais apresentaram alta similaridade (Sorensen e Bray-Curtis $>0.50$ ).

Tabela 1 - Lista florística das famílias e espécies da flora lenhosa encontradas nas áreas de estudo do Pantanal de Poconé, Mato Grosso. Abr. Abreviatura; 1. Cerrado (sensu stricto); 2. Floresta semidecidual A; 3. Floresta semidecidual B; 4. Cambarazal; e 5. Campo de murundu.

Table 1 - Floristic list of families and species of the woody flora found in the study areas of Pantanal of Poconé, Mato Grosso. Abr. Abbreviation; 1. Cerrado; 2. Semidecidual Forest A; 3. Semidecidual Forest B; 4. Cambarazal; and 5. Murundu field.

\begin{tabular}{|c|c|c|c|c|c|c|c|}
\hline Família & Espécies & Abr & 1 & 2 & 3 & 4 & 5 \\
\hline Anacardiaceae & Astronium fraxinifolium Schott & astr frax & $\mathrm{X}$ & $\mathrm{X}$ & $\mathrm{X}$ & & \\
\hline Arecaceae & Bactris glaucescens Drude & bact glau & $\mathrm{X}$ & & & & \\
\hline \multirow[t]{3}{*}{ Bignoniaceae } & Jacaranda cuspidifolia Mart. & jaca cusp & $\mathrm{X}$ & $X$ & $\mathrm{X}$ & & \\
\hline & Tabebuia heptaphylla (Vell.) Tol. & tabe hept & $\mathrm{X}$ & $\mathrm{X}$ & $\mathrm{X}$ & & \\
\hline & Tabebuia ochracea (Cham.) Stall. & tabe ochr & $\mathrm{X}$ & $\mathrm{X}$ & $\mathrm{X}$ & & \\
\hline Bombacaceae & Pseudobombax marginatum (St. Hil.) Rob. & Pseu & & $\mathrm{X}$ & $\mathrm{X}$ & & \\
\hline Boraginaceae & Cordia glabrata (Mart.) A. DC. & cord glab & $\mathrm{X}$ & $\mathrm{X}$ & $\mathrm{X}$ & & \\
\hline Chrysobalanaceae & Licania parvifolia Huber & lica parv & $\mathrm{X}$ & & & $\mathrm{X}$ & \\
\hline Clusiaceae & Garcinia brasiliensis Mart. & garc bras & & $\mathrm{X}$ & $\mathrm{X}$ & $\mathrm{X}$ & \\
\hline Combretaceae & Terminalia argentea Mart. et Zucc. & term arge & $\mathrm{X}$ & $\mathrm{X}$ & $\mathrm{X}$ & & \\
\hline Connaraceae & Connaraceae sp. 1 & conn 1 & & & $\mathrm{X}$ & & \\
\hline Dilleniaceae & Curatella americana $\mathrm{L}$. & cura amer & $\mathrm{X}$ & $X$ & & $\mathrm{X}$ & $\mathrm{X}$ \\
\hline Ebenaceae & Diospyros hispida DC. & dios hisp & $\mathrm{X}$ & $\mathrm{X}$ & $\mathrm{X}$ & & \\
\hline Erythroxylaceae & Erythroxylum anguifugum Mart. & eryt angu & $\mathrm{X}$ & $\mathrm{X}$ & $\mathrm{X}$ & $\mathrm{X}$ & \\
\hline \multirow[t]{2}{*}{ Euphorbiaceae } & Alchornea discolor Poepp. & alch disc & & $\mathrm{X}$ & & & $\mathrm{X}$ \\
\hline & Aporosella chacoensis (Mor) Speg & apor chac & & & $X$ & & \\
\hline \multirow[t]{7}{*}{ Fabaceae } & Andira inermis H. B. K. & andi iner & $\mathrm{X}$ & & $\mathrm{X}$ & $\mathrm{X}$ & \\
\hline & Bauhinia rufa (Bong.) Steud & bauh rufa & $\mathrm{X}$ & & & & \\
\hline & Depterix alata Vogel & dept alat & & & & & $\mathrm{X}$ \\
\hline & Machaerium hirtum (Vell.) Stellf. & mach hirt & $\mathrm{X}$ & $X$ & $X$ & & \\
\hline & Platymiscium pubescens Micheli & plat pube & & & $\mathrm{X}$ & & \\
\hline & Pterocarpus micheli Brit. & pter mich & $\mathrm{X}$ & $\mathrm{X}$ & $\mathrm{X}$ & & \\
\hline & Sclerolobium sp. & scl esp & & & $\mathrm{X}$ & & \\
\hline Flacourtiaceae & Casearia sylvestris Sw. Var. & case sylv & & $\mathrm{X}$ & & & \\
\hline \multirow[t]{2}{*}{ Lauraceae } & Ocatea diospyrifolia (Meisn) Mez. Velff & ocat dios & & & $\mathrm{X}$ & & \\
\hline & Ocotea suaveolens Hanl. & ocot suav & & & $\mathrm{X}$ & & \\
\hline \multirow[t]{2}{*}{ Malpighiaceae } & Byrsonima crassifolia (L.) H. B. K. & byrs cras & & & $\mathrm{X}$ & & \\
\hline & Byrsonima orbignyana A. Juss. & byrs orbi & $\mathrm{X}$ & & & & $\mathrm{X}$ \\
\hline
\end{tabular}




\begin{tabular}{|c|c|c|c|c|c|c|c|}
\hline Família & Espécies & Abr & 1 & 2 & 3 & 4 & 5 \\
\hline \multirow[t]{2}{*}{ Melastomataceae } & Mouriri elliptica Mart. & mour elli & & $\mathrm{X}$ & $\mathrm{X}$ & & \\
\hline & Mouriri guianensis Aubl. & mour irig & & $X$ & $\mathrm{X}$ & $\mathrm{X}$ & \\
\hline Meliaceae & Trichilia catigua DC. A. Juss & tric cati & & $\mathrm{X}$ & $\mathrm{X}$ & $\mathrm{X}$ & \\
\hline Moraceae & Brosimum gaudichaudii Trec. & bros gaud & $\mathrm{X}$ & $\mathrm{X}$ & $\mathrm{X}$ & $\mathrm{X}$ & \\
\hline \multirow[t]{8}{*}{ Myrtaceae } & Eugenia egensis DC. & euge ege & & & $\mathrm{X}$ & & \\
\hline & Eugenia florida DC. & euge flor & $\mathrm{X}$ & & $\mathrm{X}$ & $\mathrm{X}$ & \\
\hline & Eugenia inundata DC. & euge inun & $\mathrm{X}$ & & $\mathrm{X}$ & & $\mathrm{X}$ \\
\hline & Eugenia pyriformis Camb. & euge pyri & $\mathrm{X}$ & & $\mathrm{X}$ & & \\
\hline & Eugenia sp. & eug esp & $\mathrm{X}$ & & & & \\
\hline & Myrcia multiflora (Lam.) DC. & myrc & & & & & \\
\hline & & mult & & & & & \\
\hline & Psidium guineense Sw. & psid guin & $\mathrm{X}$ & $X$ & $\mathrm{X}$ & & \\
\hline Nyctaginaceae & Neea hermaphrodita S. Moore. & $\begin{array}{l}\text { neea } \\
\text { herm }\end{array}$ & $\mathrm{X}$ & $X$ & $\mathrm{X}$ & & \\
\hline \multirow[t]{3}{*}{ Polygonaceae } & Coccoloba cujabensis Wedd. & cocc cuja & & & & $\mathrm{X}$ & \\
\hline & Coccoloba rigida Meisn. & cocc rigi & & & & $\mathrm{X}$ & \\
\hline & Triplaris gardneriana Wedd. & trip gard & & $\mathrm{X}$ & $\mathrm{X}$ & $\mathrm{X}$ & \\
\hline \multirow[t]{6}{*}{ Rubiaceae } & Alibertia edulis Rich & alib edul & & & & & $\mathrm{X}$ \\
\hline & Chomelia obtusa Cham. Schltdl. & $\begin{array}{l}\text { chom } \\
\text { obtu }\end{array}$ & $\mathrm{X}$ & & & & \\
\hline & Duroia duckei Huber. & duro duck & & $\mathrm{X}$ & & $\mathrm{X}$ & \\
\hline & Genipa americana L. & geni amer & $\mathrm{X}$ & $\mathrm{X}$ & & $\mathrm{X}$ & \\
\hline & Randia armata (Sw.) DC. & rand arma & & $\mathrm{X}$ & $\mathrm{X}$ & $\mathrm{X}$ & \\
\hline & Rubiaceae sp. 1 & rubil & & $\mathrm{X}$ & $\mathrm{X}$ & & \\
\hline Salicaceae & Xylosma venosa N.E.Br. & $\begin{array}{l}\text { xylo } \\
\text { smav }\end{array}$ & $\mathrm{X}$ & & & & \\
\hline Sapindaceae & Magonia pubescens A. St. Hil. & $\begin{array}{l}\text { mago } \\
\text { pube }\end{array}$ & & $\mathrm{X}$ & $\mathrm{X}$ & & \\
\hline Ulmaceae & Trema micrantha (L.) Blume & trem micr & & & $\mathrm{X}$ & & $\mathrm{X}$ \\
\hline Urticaceae & Cecropia pachystachya Trecul & cecr pach & & & $\mathrm{X}$ & & \\
\hline \multirow[t]{2}{*}{ Vochysiaceae } & Callisthene fasciculata (Spr.) Mart. & call fasc & $\mathrm{X}$ & $X$ & $\mathrm{X}$ & & \\
\hline & Vochysia divergens Pohl. & voch dive & & & $\mathrm{X}$ & $X$ & $\mathrm{X}$ \\
\hline
\end{tabular}

Os descritores quantitativos da comunidade das quatro fitofisionomias estudadas são apresentados na Tabela 2 e nota-se que as formações semideciduais apresentaram maiores valores e que cambarazal e campo de murundu apresentaram menores números de espécies e indivíduos o que pode ter influenciado nos valores de diversidade.

$\mathrm{Na}$ área de Cerrado as espécies com maiores valores de importância foram Diospyros hispida, Erythroxylum anguifugum, Curatella americana,
Callisthene fasciculata, Tabebuia ochracea e Tabebuia heptaphylla, respectivamente (Tab. $3)$. As espécies $D$. hispida e E. anguifugum apresentaram maiores números de indivíduos e maiores valores de densidade e frequência relativas o que influenciou nos maiores valores de importância. As espécies C. americana, $C$. fasciculata e $T$. ochracea tiveram seus valores de importâncias influenciados pela densidade e dominância relativas e Tabebuia heptaphylla o IVI foi influenciado pelo valor de dominância relativa. 

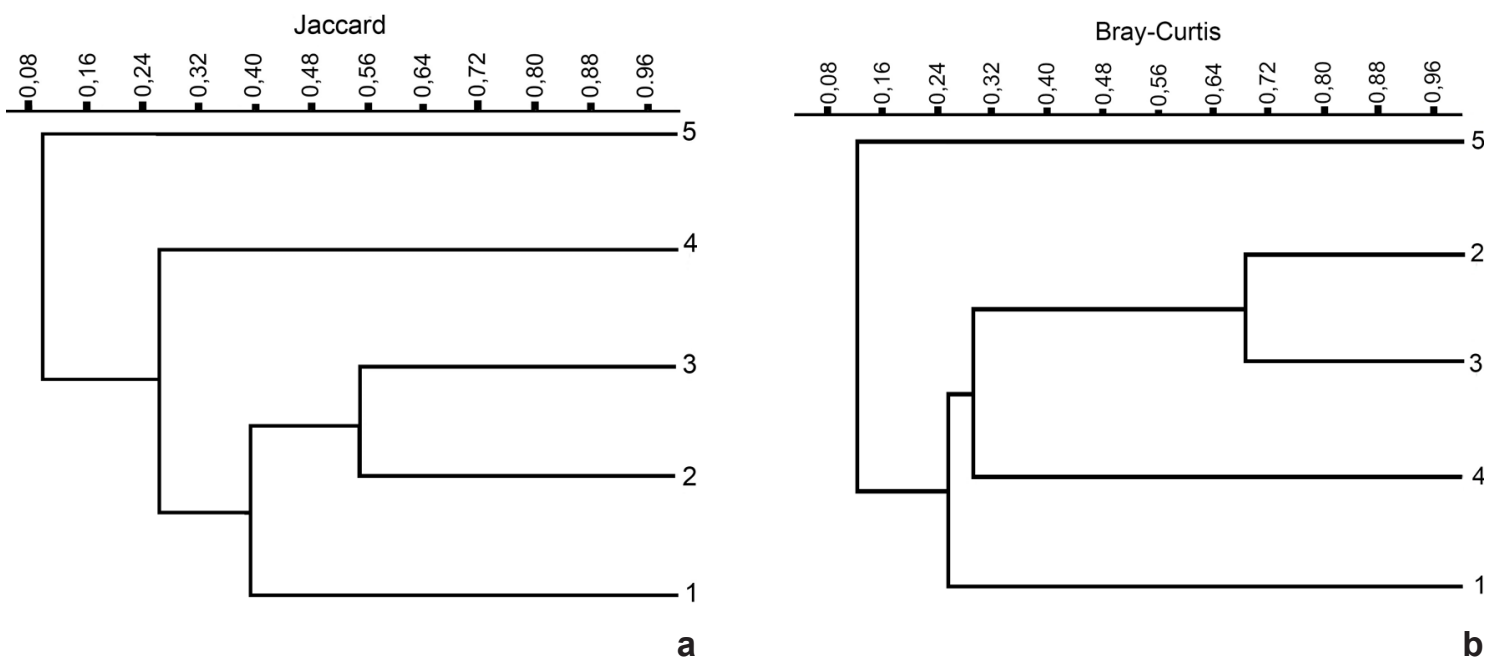

Figura 1 - Dendrograma de similaridade entre as fitofisionomias (a) Similaridade com base na matriz de presença e ausência (b) similaridade com base na matriz de abundância das espécies, Pantanal de Poconé-MT. 1. Cerrado; 2. Floresta semidecidual A; 3. Floresta semidecidual B; 4. Cambarazal; e 5. Campo de murundu. Figure 1 - Dendogram of similarity among phyto-phygsionomies (a) Similarity based on the matrix of presence and absence (b) similarity based on teh matrix of abundance of species, Pantanal of Poconé-MT. 1. Cerrado; 2. Semidecidual Forest A; 3. Semidecidual Forest B; 4. Cambarazal; and 5. Murundu field.

Tabela 2 - Valores de abundância, família, riqueza, índice de diversidade Shannon (H') e equitabilidade de Pielou (J') das fitofisionomias estudadas no Pantanal de Poconé, MT.

Table 2 - Abundance value, richness, Shannon's diversity index (H') and Pielou's equitability index (J') of the studied phytophygsionomies at Pantanal of Poconé, MT.

\begin{tabular}{lccccc}
\hline Fitofisionomia & Abundância total & Família & Riqueza & H' & J' \\
\hline Cerrado (sensu stricto) & 393 & 17 & 27 & 2,33 & 0,71 \\
Floresta semidecidual A & 528 & 20 & 28 & 2,26 & 0,69 \\
Floresta semidecidual B & 658 & 23 & 38 & 2,62 & 0,72 \\
Cambarazal & 311 & 12 & 16 & 2,18 & 0,78 \\
Campo de Murundu & 145 & 8 & 8 & 1,35 & 0,70 \\
\hline
\end{tabular}

$\mathrm{Na}$ floresta semidecidual A as espécies Trichilia catigua e Mouriri guianensis apresentaram maior abundância e os valores de importância foram influenciados pelos maiores valores de densidade, frequência e dominância relativas. As espécies Brosimum gaudichaudi e $E$. anguifugum tiveram seus valores de importância relacionados aos densidade e frequência relativas e T. heptaphylla e Pseudobombax marginatum os valores de IVI estão relacionados aos valor de dominância (Tab. 4).

$\mathrm{Na}$ formação semidecidual $\mathrm{B}$ as espécies Garcinia brasiliensis, T. catigua, M. guianensis, T. heptaphylla, E. anguifugum, B. gaudichaudii apresentam maiores valores de importância que foram influenciado pelos valores de FR, DR e DoR (Tab. 5).

No Cambarazal a espécies mais importantes foram Vochysia divergens, Coccoloba cujabensis, $M$. guianensis, E. anguifugum e B. gaudichaudii (Tab. 6). Vochysia divergens apresentou maior valor de IVI por apresentar maiores valores de densidade, frequência e dominância relativa. As demais espécies acima mencionadas tiveram seu índice de valor de importância influenciado pelos valores de densidade e frequência relativas.

No Campo de murundu as espécies $C$. americana, $V$. divergens, Alchornea discolor $\mathrm{e}$ 
Tabela 3 - Parâmetros fitossociológicos da vegetação lenhosa da área de Cerrado ( $\mathrm{N}=$ abundância total; $\mathrm{DR}=$ Densidade relativa; $\mathrm{FR}=$ Frequência relativa; $\mathrm{DoR}=$ Dominância relativa; $\mathrm{IVI}=$ Índice de valor de importância; $\mathrm{IVC}=$ índice de valor de cobertura).

Table 3 - Phytosociological parameters of the woody vegetation of the Cerrado area ( $N=$ total abundance; $\mathrm{DR}=$ Relative density; $\mathrm{FR}=$ Relative frequency; DoR= Relative dominance; IVI= Importance value index; IVC= coverage value index).

\begin{tabular}{|c|c|c|c|c|c|c|}
\hline Espécies & $\mathbf{N}$ & DR & FR & DoR & IVI & IVC \\
\hline Diospyros hispida & 125 & 31,81 & 14,74 & 8,98 & 55,53 & 40,78 \\
\hline Erythroxylum anguifugum & 67 & 17,05 & 15,38 & 7,29 & 39,72 & 24,33 \\
\hline Curatella americana & 24 & 6,11 & 10,9 & 21,06 & 38,07 & 27,17 \\
\hline Callisthene fasciculata & 42 & 10,69 & 7,05 & 17,52 & 35,26 & 28,2 \\
\hline Tabebuia ochracea & 21 & 5,34 & 7,05 & 18,24 & 30,63 & 23,58 \\
\hline Tabebuia heptaphylla & 8 & 2,04 & 3,85 & 13,98 & 19,86 & 16,01 \\
\hline Bactris glaucescens & 31 & 7,89 & 5,77 & 1,23 & 14,89 & 9,12 \\
\hline Psidium guineense & 15 & 3,82 & 7,05 & 0,57 & 11,44 & 4,39 \\
\hline Genipa americana L. & 7 & 1,78 & 3,85 & 1,78 & 7,41 & 3,56 \\
\hline Byrsonima orbignyana & 8 & 2,04 & 3,21 & 1,05 & 6,29 & 3,09 \\
\hline Neea hermaphrodita & 9 & 2,29 & 3,21 & 0,53 & 6,02 & 2,82 \\
\hline Jacaranda cuspidifolia & 6 & 1,53 & 1,92 & 1,94 & 5,39 & 3,47 \\
\hline Brosimum gaudichaudii & 6 & 1,53 & 2,56 & 1,22 & 5,32 & 2,75 \\
\hline Bauhinia rufa & 4 & 1,02 & 2,56 & 0,18 & 3,77 & 1,2 \\
\hline Astronium fraxinifolium & 2 & 0,51 & 1,28 & 1,64 & 3,43 & 2,15 \\
\hline Chomelia obtusa & 3 & 0,76 & 1,92 & 0,13 & 2,81 & 0,89 \\
\hline Cordia glabrata & 2 & 0,51 & 0,64 & 1,42 & 2,57 & 1,93 \\
\hline Machaerium hirtum & 2 & 0,51 & 1,28 & 0,22 & 2,01 & 0,73 \\
\hline Eugenia inundata & 2 & 0,51 & 0,64 & 0,12 & 1,27 & 0,63 \\
\hline Terminalia argentea & 1 & 0,25 & 0,64 & 0,35 & 1,24 & 0,6 \\
\hline Eugenia pyriformis & 2 & 0,51 & 0,64 & 0,09 & 1,24 & 0,6 \\
\hline Pterocarpus micheli & 1 & 0,25 & 0,64 & 0,21 & 1,1 & 0,46 \\
\hline Licania parvifolia & 1 & 0,25 & 0,64 & 0,09 & 0,98 & 0,34 \\
\hline Andira inermis & 1 & 0,25 & 0,64 & 0,07 & 0,97 & 0,33 \\
\hline Eugenia florida & 1 & 0,25 & 0,64 & 0,04 & 0,93 & 0,29 \\
\hline Xylosma venosa & 1 & 0,25 & 0,64 & 0,03 & 0,93 & 0,29 \\
\hline Eugenia sp. & 1 & 0,25 & 0,64 & 0,03 & 0,92 & 0,28 \\
\hline Total & 393 & 100 & 100 & 100 & ---- & ---- \\
\hline
\end{tabular}

Dipteryx alata, apresentaram maiores valores de importância (Tab. 7). Nesta fitofisionomia a espécie C. americana é monodominante e os valores de densidade, frequência e dominância relativa determinam-lhe o alto valor de importância. Os valores de importância de $A$. discolor e D. alata o valor de importância estão relacionados aos respectivos valores de densidade e frequência relativa.

$\mathrm{Na}$ área de formação savânica (Fig. 2a) e murundu (Fig. 2e) os intervalos de altura são similares. Na formação savânica $96 \%$ dos indivíduos (381 ind.) encontram-se nas três primeiras classes de altura e no campo de 
Tabela 4 - Parâmetros fitossociológicos da vegetação lenhosa da área de Floresta semidecidual A ( $\mathrm{N}=$ abundância total; $\mathrm{DR}=$ Densidade relativa; $\mathrm{FR}=$ Frequência relativa; DoR= Dominância relativa; IVI= Índice de valor de importância; IVC=índice de valor de cobertura).

Table 4 - Phytosociological parameters of the woody vegetation of the Semidecidual Forest A area ( $N=$ total abundance; $\mathrm{DR}=\mathrm{Re}$ lative density; FR= Relative frequency; DoR= Relative dominance; IVI= Importance value index; IVC= coverage value index).

\begin{tabular}{|c|c|c|c|c|c|c|}
\hline Espécies & $\mathbf{N}$ & DR & FR & DoR & IVI & IVC \\
\hline Trichilia catigua & 162 & 30,86 & 14,2 & 15,03 & 60,08 & 45,88 \\
\hline Mouriri guianensis & 99 & 18,86 & 13,02 & 22,86 & 54,74 & 41,72 \\
\hline Tabebuia heptaphylla & 23 & 4,38 & 6,51 & 23,1 & 33,99 & 27,48 \\
\hline Brosimum gaudichaudii & 48 & 9,14 & 11,24 & 5,12 & 25,51 & 14,26 \\
\hline Pseudobombax marginatum & 21 & 4 & 7,69 & 13,06 & 24,76 & 17,06 \\
\hline Erythroxylum anguifugum & 63 & 12 & 8,88 & 3,34 & 24,22 & 15,34 \\
\hline Machaerium hirtum & 24 & 4,57 & 6,51 & 4,49 & 15,57 & 9,06 \\
\hline Garcinia brasiliensis & 23 & 4,38 & 5,33 & 3,56 & 13,26 & 7,94 \\
\hline Triplaris gardneriana & 13 & 2,48 & 3,55 & 1,33 & 7,36 & 3,81 \\
\hline Tabebuia ochracea & 7 & 1,33 & 3,55 & 1,98 & 6,87 & 3,32 \\
\hline Genipa americana & 6 & 1,14 & 2,96 & 1,82 & 5,92 & 2,96 \\
\hline Cordia glabrata & 4 & 0,76 & 2,37 & 0,66 & 3,79 & 1,42 \\
\hline Astronium fraxinifolium & 6 & 1,14 & 1,78 & 0,27 & 3,19 & 1,41 \\
\hline Jacaranda cuspidifolia & 3 & 0,57 & 1,78 & 0,74 & 3,09 & 1,31 \\
\hline Myrcia multiflora & 4 & 0,76 & 1,18 & 0,11 & 2,05 & 0,87 \\
\hline Alchornea discolor & 3 & 0,57 & 1,18 & 0,15 & 1,9 & 0,72 \\
\hline Randia armata & 3 & 0,57 & 1,18 & 0,05 & 1,8 & 0,62 \\
\hline Magonia pubescens & 1 & 0,19 & 0,59 & 0,9 & 1,68 & 1,09 \\
\hline Rubiaceae 1 & 2 & 0,38 & 1,18 & 0,04 & 1,6 & 0,42 \\
\hline Terminalia argentea & 1 & 0,19 & 0,59 & 0,42 & 1,2 & 0,61 \\
\hline Callisthene fasciculata & 1 & 0,19 & 0,59 & 0,35 & 1,13 & 0,54 \\
\hline Psidium guineense & 2 & 0,38 & 0,59 & 0,08 & 1,06 & 0,46 \\
\hline Duroia duckei & 1 & 0,19 & 0,59 & 0,23 & 1,01 & 0,42 \\
\hline Pterocarpus micheli & 1 & 0,19 & 0,59 & 0,1 & 0,88 & 0,29 \\
\hline Casearia sylvestris & 1 & 0,19 & 0,59 & 0,1 & 0,88 & 0,29 \\
\hline Mouriri elliptica & 1 & 0,19 & 0,59 & 0,06 & 0,85 & 0,25 \\
\hline Diospyros hispida & 1 & 0,19 & 0,59 & 0,04 & 0,82 & 0,23 \\
\hline Neea hermaphrodita & 1 & 0,19 & 0,59 & 0,03 & 0,81 & 0,22 \\
\hline Total & 525 & 100 & 100 & 100 & ---- & ---- \\
\hline
\end{tabular}

murundu em 98\% dos indivíduos (200 ind.). As duas fitofisionomias apresentaram maior quantidade de indivíduos até 3 metros de altura. As fitofisionomias formações semideciduais (Figs. 2b,c) e o cambarazal (Fig. 2d) apresentam padrões semelhantes com maior quantidade de indivíduos entre 3 a 7 metros de altura. $\mathrm{Na}$ formação semidecidual A 93\% dos indivíduos (503 ind.) encontram-se nas três primeiras classes de altura e a formação semidecidual B $95 \%$ dos 
Tabela 5 - Parâmetros fitossociológicos da vegetação lenhosa da área de floresta semidecidual $\mathrm{B}(\mathrm{N}=$ abundância total; $\mathrm{DR}=$ Densidade relativa; $\mathrm{FR}=$ Frequência relativa; $\mathrm{DoR}=$ Dominância relativa; $\mathrm{IVI}=$ Índice de valor de importância; $\mathrm{IVC}=$ índice de valor de cobertura).

Table 5 - Phytosociological parameters of the woody vegetation of the Semidecidual Forest $\mathrm{B}$ area ( $\mathrm{N}=$ total abundance; $\mathrm{DR}=\mathrm{Relative}$ density; FR= Relative frequency; DoR= Relative dominance; IVI= Importance value index; IVC= coverage value index).

\begin{tabular}{|c|c|c|c|c|c|c|}
\hline Espécies & $\mathbf{N}$ & DR & FR & DoR & IVI & IVC \\
\hline Garcinia brasiliensis & 105 & 15,96 & 8,97 & 14,71 & 39,64 & 30,67 \\
\hline Trichilia catigua & 98 & 14,89 & 10,26 & 11,97 & 37,12 & 26,87 \\
\hline Erythroxylum anguifugum & 117 & 17,78 & 10,26 & 7,64 & 35,68 & 25,42 \\
\hline Mouriri guianensis & 82 & 12,46 & 8,97 & 11,28 & 32,72 & 23,74 \\
\hline Brosimum gaudichaudii & 54 & 8,21 & 8,55 & 7,27 & 24,03 & 15,48 \\
\hline Tabebuia heptaphylla & 10 & 1,52 & 3,42 & 10,99 & 15,93 & 12,51 \\
\hline Machaerium hirtum & 37 & 5,62 & 4,27 & 5,89 & 15,79 & 11,51 \\
\hline Triplaris gardneriana & 27 & 4,1 & 5,98 & 2,24 & 12,32 & 6,34 \\
\hline Andira inermis & 12 & 1,82 & 4,27 & 3,94 & 10,04 & 5,76 \\
\hline Genipa americana & 12 & 1,82 & 3,85 & 1,31 & 6,98 & 3,14 \\
\hline Eugenia egensis & 11 & 1,67 & 2,99 & 1,69 & 6,36 & 3,36 \\
\hline Mouriri elliptica & 7 & 1,06 & 1,71 & 3,32 & 6,09 & 4,38 \\
\hline Pseudobombax marginatum & 7 & 1,06 & 2,56 & 1,91 & 5,54 & 2,97 \\
\hline Jacaranda cuspidifolia & 6 & 0,91 & 1,71 & 1,87 & 4,49 & 2,78 \\
\hline Diospyros hispida & 7 & 1,06 & 2,14 & 1,2 & 4,41 & 2,27 \\
\hline Neea hermaphrodita & 10 & 1,52 & 1,71 & 0,88 & 4,11 & 2,4 \\
\hline Psidium guineense & 5 & 0,76 & 2,14 & 0,84 & 3,74 & 1,6 \\
\hline Astronium fraxinifolium & 7 & 1,06 & 1,71 & 0,83 & 3,6 & 1,89 \\
\hline Tabebuia ochracea & 3 & 0,46 & 1,28 & 1,39 & 3,12 & 1,84 \\
\hline Randia armata & 5 & 0,76 & 1,28 & 0,75 & 2,79 & 1,51 \\
\hline Eugenia pyriformis & 5 & 0,76 & 1,28 & 0,65 & 2,69 & 1,41 \\
\hline Cordia glabrata & 4 & 0,61 & 1,28 & 0,69 & 2,58 & 1,3 \\
\hline Ocatea diospyrifolia & 4 & 0,61 & 1,28 & 0,53 & 2,42 & 1,13 \\
\hline Platymiscium pubenscens & 1 & 0,15 & 0,43 & 1,7 & 2,27 & 1,85 \\
\hline Vochysia divergens & 2 & 0,3 & 0,85 & 1,07 & 2,23 & 1,37 \\
\hline Ocotea suaveolens & 2 & 0,3 & 0,85 & 0,53 & 1,68 & 0,83 \\
\hline Callisthene fasciculata & 2 & 0,3 & 0,85 & 0,52 & 1,68 & 0,83 \\
\hline Trema micrantha & 4 & 0,61 & 0,43 & 0,32 & 1,35 & 0,92 \\
\hline Byrsonima crassifolia & 2 & 0,3 & 0,85 & 0,1 & 1,26 & 0,41 \\
\hline Cecropia pachystachya & 2 & 0,3 & 0,43 & 0,49 & 1,22 & 0,79 \\
\hline Aporosella chacoensis & 1 & 0,15 & 0,43 & 0,6 & 1,18 & 0,76 \\
\hline Magonia pubescens & 1 & 0,15 & 0,43 & 0,46 & 1,03 & 0,61 \\
\hline Pterocarpus micheli & 1 & 0,15 & 0,43 & 0,18 & 0,76 & 0,33 \\
\hline Eugenia florida & 1 & 0,15 & 0,43 & 0,09 & 0,67 & 0,24 \\
\hline
\end{tabular}




\begin{tabular}{lcccccc}
\hline Espécies & N & DR & FR & DoR & IVI & IVC \\
\hline Ponnaraceae 1 & 1 & 0,15 & 0,43 & 0,07 & 0,65 & 0,22 \\
Sclerolobium sp. & 1 & 0,15 & 0,43 & 0,04 & 0,62 & 0,19 \\
Rubiaceae 1 & 1 & 0,15 & 0,43 & 0,03 & 0,61 & 0,18 \\
Eugenia inundata & 1 & 0,15 & 0,43 & 0,02 & 0,6 & 0,17 \\
\hline Total & 658 & 100 & 100 & 100 & ---- & ---- \\
\hline
\end{tabular}

Tabela 6 -Parâmetros fitossociológicos da vegetação lenhosa da área de Cambarazal ( $\mathrm{N}=$ abundância total; $\mathrm{DR}=$ Densidade relativa; FR= Frequência relativa; $\mathrm{DoR}=$ Dominância relativa; $\mathrm{IVI}=$ Índice de valor de importância; IVC=índice de valor de cobertura). Table 6 - Phytosociological parameters of the woody vegetation of the Cambarazal area $(\mathrm{N}=$ total abundance; $\mathrm{DR}=\mathrm{Re}$ lative density; $\mathrm{FR}=$ Relative frequency; DoR= Relative dominance; IVI= Importance value index; IVC= coverage value index .

\begin{tabular}{lcccccc}
\hline Espécies & N & DR & FR & DoR & IVI & IVC \\
\hline Vochysia divergens & 64 & 20,58 & 19,82 & 77,82 & 118,22 & 98,4 \\
Coccoloba cujabensis & 64 & 20,58 & 13,51 & 4,16 & 38,25 & 24,73 \\
Mouriri guianensis & 38 & 12,22 & 10,81 & 5,03 & 28,06 & 17,25 \\
Erythroxylum anguifugum & 33 & 10,61 & 14,41 & 1,02 & 26,05 & 11,63 \\
Brosimum gaudichaudii & 30 & 9,65 & 11,71 & 3,07 & 24,43 & 12,72 \\
Licania parvifolia & 20 & 6,43 & 8,11 & 4,28 & 18,82 & 10,72 \\
Triplaris gardneriana & 30 & 9,65 & 8,11 & 1,03 & 18,79 & 10,68 \\
Eugenia florida & 15 & 4,82 & 2,7 & 1,81 & 9,34 & 6,64 \\
Randia armata & 4 & 1,29 & 2,7 & 0,27 & 4,26 & 1,55 \\
Duroia duckei & 4 & 1,29 & 2,7 & 0,17 & 4,16 & 1,45 \\
Coccoloba rigida & 4 & 1,29 & 0,9 & 0,55 & 2,74 & 1,83 \\
Trichilia catigua & 1 & 0,32 & 0,9 & 0,64 & 1,86 & 0,96 \\
Genipa americana & 1 & 0,32 & 0,9 & 0,05 & 1,28 & 0,37 \\
Garcinia brasiliensis & 1 & 0,32 & 0,9 & 0,04 & 1,27 & 0,36 \\
Myrcia multiflora & 1 & 0,32 & 0,9 & 0,03 & 1,25 & 0,35 \\
Andira inermis & 1 & 0,32 & 0,9 & 0,02 & 1,24 & 0,34 \\
\hline Total & 311 & 100 & 100 & 100 & ---- & ---- \\
\hline
\end{tabular}

Tabela 7-Parâmetros fitossociológicos da vegetação lenhosa da área de campo de Murundu ( $\mathrm{N}=$ abundância total; $\mathrm{DR}=$ Densidade relativa; $F R=$ Frequência relativa; $\mathrm{DoR}=$ Dominância relativa; $\mathrm{IVI}=$ Índice de valor de importância; $\mathrm{IVC}=$ ='́ndice de valor de cobertura). Table 7 - Phytosociological parameters of the woody vegetation Murundu Field ( $N=$ total abundance; $\mathrm{DR}=$ Relative density; $\mathrm{FR}=$ Relative frequency; DoR= Relative dominance; IVI= Importance value index; IVC= coverage value index).

\begin{tabular}{lcccccc}
\hline Espécies & N & DR & FR & DoR & IVI & IVC \\
\hline Curatella americana & 79 & 54,48 & 34,21 & 75,12 & 163,81 & 129,6 \\
Vochysia divergens & 15 & 10,34 & 15,79 & 9,78 & 35,91 & 20,12 \\
Alchornea discolor & 32 & 22,07 & 23,68 & 6,13 & 51,88 & 28,19 \\
Depterix alata & 2 & 1,38 & 2,63 & 3,99 & 8 & 5,37 \\
Alibertia edulis & 6 & 4,14 & 2,63 & 2,15 & 8,92 & 6,28 \\
\hline
\end{tabular}




\begin{tabular}{lcccccc}
\hline Espécies & N & DR & FR & DoR & IVI & IVC \\
\hline Birsonima orbignyana & 7 & 4,83 & 10,53 & 1,72 & 17,08 & 6,55 \\
Cecropia pachystachya & 3 & 2,07 & 7,89 & 0,91 & 10,88 & 2,98 \\
Eugenia inundata & 1 & 0,69 & 2,63 & 0,21 & 3,53 & 0,9 \\
\hline Total & 145 & 100 & 100 & 100 & --- & ---- \\
\hline
\end{tabular}

indivíduos (643 ind.). No cambarazal 78\% dos indivíduos (259 ind.) estão distribuídos nas três primeiras classes de altura.

A distribuição dos indivíduos por classe diamétrica (Fig. 3) apresenta o formato da curva do tipo $\mathrm{J}$ invertido para todas as fitofisionomias.

A análise de DCA (Fig. 4) expressou uma mudança significativa na composição das espécies.

Entre as fitofisionomias estudadas o eixo 1 capturou 0,597 da variação e o eixo 20,283 . As subparcelas 1 a 25 são aquelas implantadas na área de Cerrado, as subparcelas de 26 a 75 são as implantadas na área de Mata Semidecidual que ficam até três meses alagadas, as subparcelas de 76 a 100 são as subparcelas instaladas em Cambarazal, e as de número 101 a 113 representam a fitofisionomia de Campo de Murundu.

Na TWINSPAN (Fig. 5), na divisão 1 (autovalor 0,638), houve a separação das áreas de Cerrado, Florestas Semideciduais e Cambarazal do Campo de Murundu. Na divisão 2 (autovalor 0,564 ) ocorreu a divisão das fitofisionomias não alagadas (Cerrado) das alagáveis (Floresta decidual e Cambarazal). Na divisão 4 (autovalor 0,481 ) ocorreu a separação das Florestas Semideciduais em relação ao Cambarazal.

A área de formação savânica é caracterizada pela ausência de inundação, plantas de menores alturas e diâmetros e presença de Poaceae (apesar de não terem sido aqui amostradas). Borges \& Shepherd (2005) e Costa et al. (2010) também encontraram o mesmo padrão de altura e diâmetro e indicam que os gêneros Byrsonima, Eugenia e Tabebuia contribuem para riqueza específica, são importantes para áreas de cerrado no Pantanal e ocorrem em locais geralmente com ausência de inundação.

Nas florestas semidecidual A e B e Cambarazal a vegetação apresenta a formação de sub-bosques e emergentes. Comparando a área de cerrado com as de formações semideciduais ocorreram 15 espécies em comum (Tab. 1) o que pode indicar que estas espécies podem ser tolerantes a inundação. O presente trabalho corrobora com Abdon et al. (1998) que classificam dentre os principais gêneros de floresta estacional semidecidual para o Pantanal Tabebuia e Trichilia. As espécies pertencentes as estes gêneros estão entre as que apresentaram maiores valores de importância no presente estudo.

O Cambarazal em comparação com área de Cerrado sensu stricto apresentaram seis espécies em comum e 12 espécies comuns relação às Florestas Semideciduais (Tab. 1), o que pode indicar que espécies de áreas de Florestas Semidecidual podem ser mais tolerantes a inundação em relação às espécies de áreas de Cerrado. Arieira \& Cunha (2006) indicam que as espécies Vochysia divergens, Mouriri guianensis, Licania parvifolia e Brosimum gaudichaudii contribuem para a riqueza do Cambarazal e ocorrem em áreas úmidas, estando entre as que apresentaram maior valor de importância no presente trabalho.

O Campo de Murundu é caracterizado por uma planície de inundação onde encontram-se distribuídos os murundus, local onde a vegetação lenhosa se estabelece devido a ausência de inundação dos murundus. Segundo Resende et al. (2004) e Marimon et al. (2012), esse microrrelevo apresenta solo e vegetação diferentes da área circundante pois são constituídos por uma área plana inundável, onde se encontram os morrotes que não inundam, limitando assim a distribuição de plantas lenhosas a esses pontos mais altos. Muitos autores defendem que os campos de murundus ocorrem em áreas de ecótono floresta/ cerrado (Eiten 1972; Furley 1986; Oliveira-Filho 1992), o que pode justificar as diferenças florística com as demais fitofisionomias estudadas. Os resultados desta pesquisa vem de acordo com Almeida et al. (2001) e Nasser et al. (2008) que indicam Curatella americana, Vochysia divergens, Byrsonima orbignyana, Dipteryx alata como as espécies que colonizam os Campos de Murundus e neste trabalho estão entre as espécies com maior IVI. 

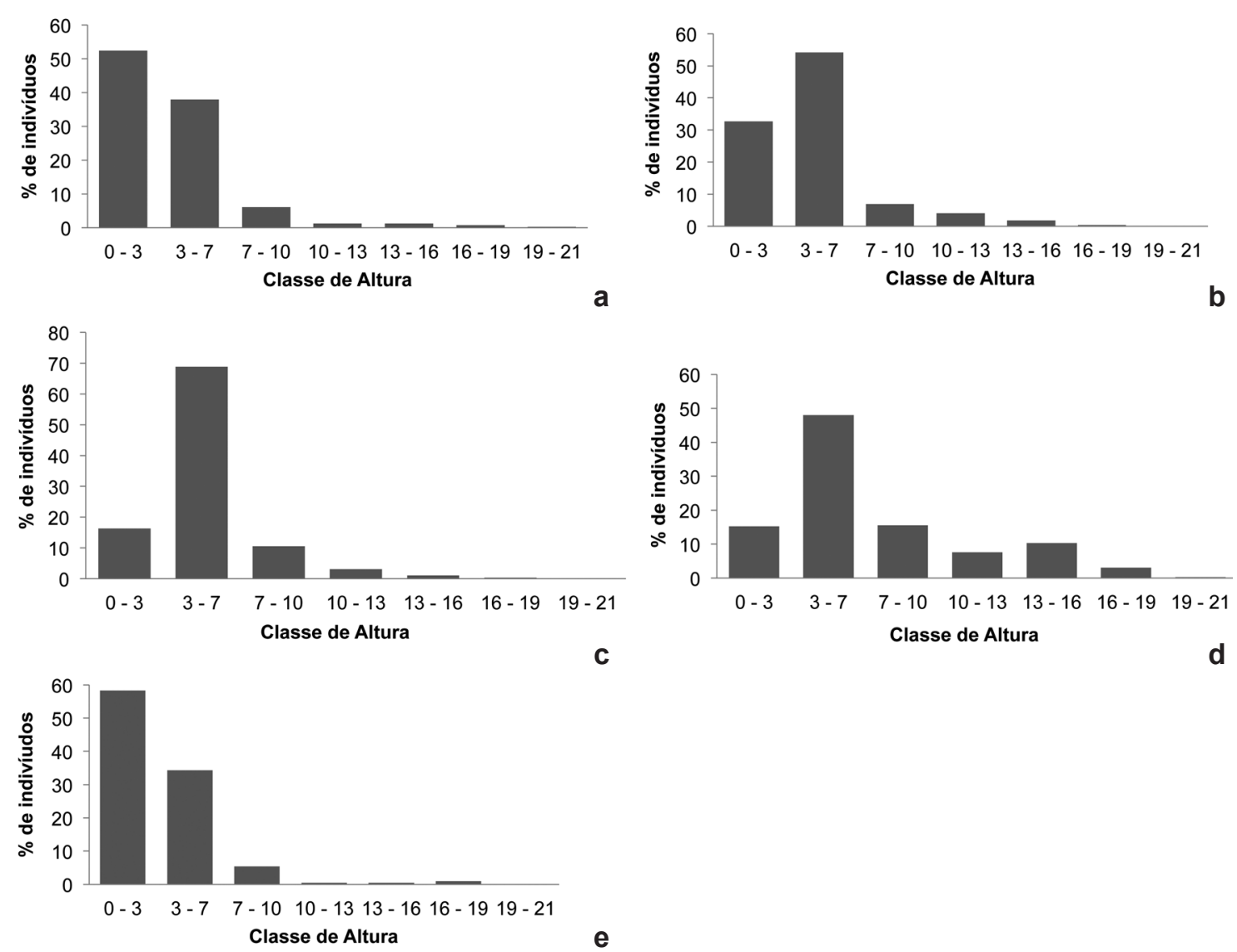

e

Figura 2 - Classe de altura para as fitofisionomias estudadas (a) formação savânica, (b) e (c) Floresta Semidecidual A (b), floresta semidecial B(c) (d) Cambarazal e (e) Campo de Murundu no Pantanal de Poconé, Mato Grosso. Figure 2 - Height interval for the studied phyto-phygsionomies (a) savannah formation, (b) and (c) semidecidual formation (d) Cambarazal and (e) Murundu Field at Pantanal of Poconé, Mato Grosso.

Em relação à estrutura do diâmetro as fitofisionomias apresentam o padrão $\mathrm{J}$ invertido que podem ser reflexos de que os indivíduos adultos mantém produção contínua de jovens e as condições do ambiente permite um aumento no potencial de recrutamento dos indivíduos jovens. O padrão da curva em J invertido é indicativo do balanço positivo entre recrutamento e mortalidade e caracteriza a comunidade como autorregenerante e é típico de áreas de formações naturais (Morais et al. 2011).

A distribuição dos indivíduos por altura indicou a existência de sub-bosque para as Florestas Semideciduais e Cambarazal e uma densa quantidade de emergentes uma vez que e as concentrações de indivíduos ficam entre 3 a 7 metros, entanto com algumas emergentes que podem chegar a 18 metros. No Cerrado sensu stricto, e Campo de Murundu ocorrem maior concentração de indivíduos até 3 metros de altura, no entanto, houve a presença de indivíduos com até 16 metros de altura. De acordo com Gottsberger \& Silberbauer-Gottsberger (2006), o Cerrado sensu stricto é dominado por árvores e arbustos com dossel geralmente menor que $7 \mathrm{~m}$.

Referente à estrutura da comunidade na região de cerrado sensu stricto no Pantanal, a espécie Curatella america e os gêneros Byrsonima e Tabebuia são representativos na composição e estrutura e o mesmo é indicado nesta pesquisa e corrobora com Borges e Shepherd (2005), Padilha et al. (2008) e Costa et al. (2010).

Nas fitofisionomia semideciduais, houve similaridade, provavelmente, devido à proximidade das áreas e o tempo de influência do pulso de inundação. As espécies que mais importantes foram: 

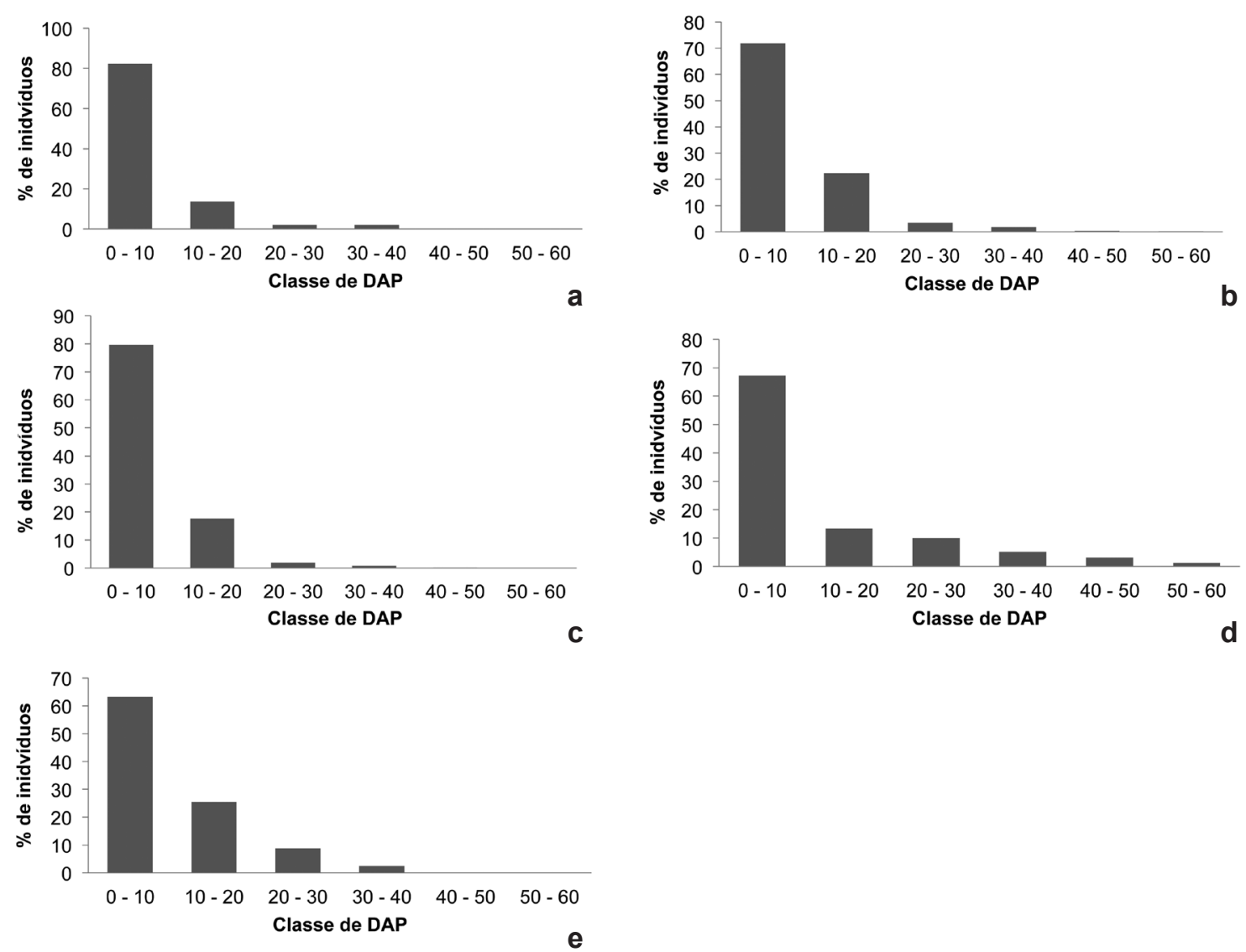

Figura 3 - Intervalo de diâmetro para as fitofisionomias estudadas (a) Cerrado, Floresta Semidecidual A(b), floresta semidecial B(c) (d) Cambarazal e (e) Campo de Murundu no Pantanal de Poconé, Mato Grosso.

Figure 3 - Diameter interval for the studied phyto-phygsionomies (a) Cerrado, (b) and (c) Semidecidual Forest (d) Cambarazal and (e) Murundu Field at Pantanal of Poconé, Mato Grosso.

Trichilia catigua, Mouriri guianensis, Tabebuia heptaphylla, Garcinia brasiliensis e Pseudobombax marginatum, pois apresentaram maiores valores de índice de importância. Silva et al. (2000) apontam os gêneros deste trabalho Tabebuia e Trichilia como os mais representativos na composição e estrutura em formação semidecídual para o Pantanal.

No Cambarazal pode-se verificar que Vochysia divergens é a espécie mais importante devido aos altos valores de DR, FR e DoR. Nascimento \& Cunha (1989) e Arieira \& Cunha (2006) indicam que em Cambarazal, Vochysia divergens apresenta altos valores de dominância. Junk (1989) aponta que o menor número de espécies encontradas no Cambarazal em comparação com as demais fitofisionomias pode estar relacionado, possivelmente, com a saturação hídrica do solo no período de cheia, o que pode limitar o estabelecimento das espécies vegetais.
No Campo de Murundu a espécie Curatella americana foi monodominante. Oliveira-Filho (1992), também indica o mesmo padrão. Cunha \& Junk (1999) citam Curatella americana para o grupo das espécies de ampla distribuição no gradiente de inundação, sendo predominante nos Campos de Murundus por resistirem a curtos períodos de inundação. Os resultados corroboram com Resende et al. (2004) que abordam que $C$. americana é mais importante em murundus do Pantanal, e os autores ainda indicam que e é uma das espécies mais tolerantes à variação sazonal na saturação hídrica do solo.

Com base na análise de DCA e TWISPAN, houve a separação de áreas não inundáveis (Cerrado sensu stricto), área não inundável circundada por planície de inundação (Campo de Murundu) e áreas inundáveis (Cambarazal e Floresta Semidecidual). Desse modo, o 


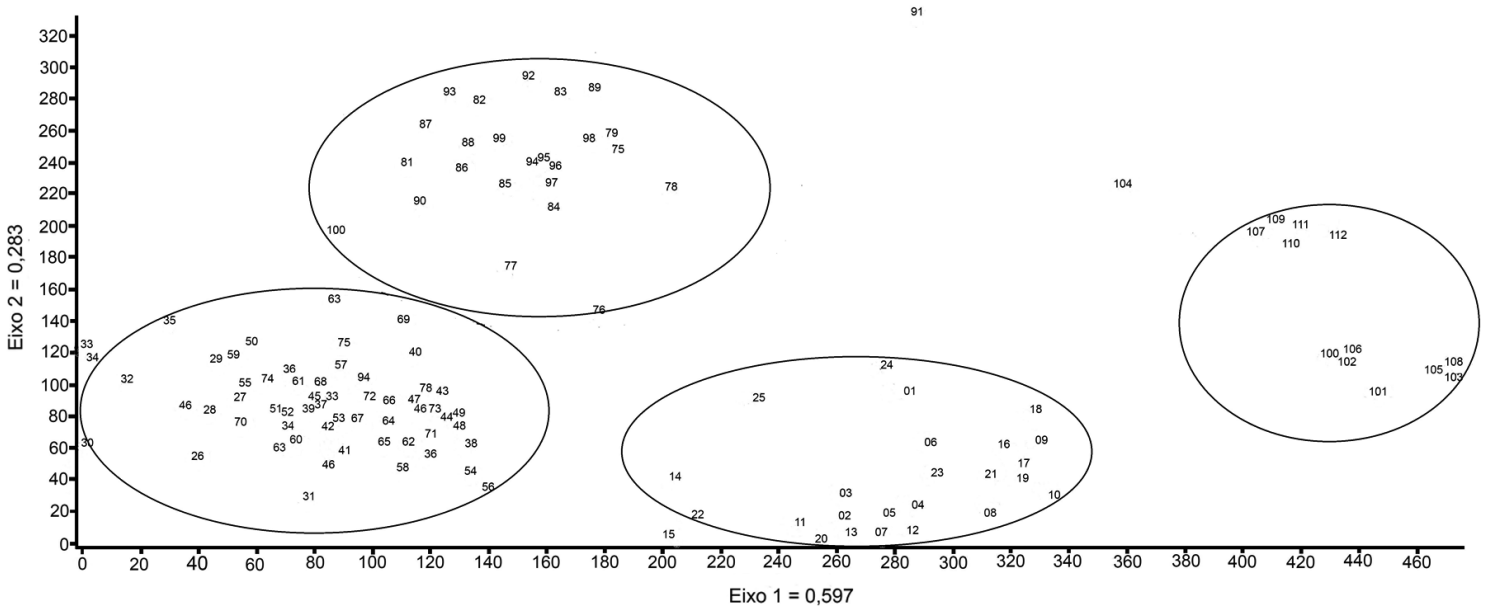

Figura 4 - Ordenação obtida para os dois primeiros eixos da análise de correspondência distendida (DCA), com base nos dados de abundância das espécies por subparcela, Pantanal de Poconé, Mato Grosso.

Figure 4 - Ordination obtained for the two first axes of analysis of distended correspondence (DCA), based on the abundance data of species per subplot, Pantanal of Poconé, Mato Grosso.

pulso de inundação pode ser responsável pelas formações de habitats e nichos que propiciam a heterogeneidade espacial, o que pode determinar a distribuição das espécies e a formação de um mosaico da paisagem. Junk (1989) e Nunes da Cunha \& Junk (2001) indicam que em áreas úmidas, como o Pantanal, a composição florística e estrutura da comunidade vegetal respondem principalmente ao pulso de inundação.

Neste contexto, algumas espécies, que possuem sua distribuição influenciada por condições determinadas pelo pulso de inundação, como as indicadas neste trabalho, podem ser utilizadas como indicadoras destas fitofisionomias e do efeito de possíveis mudanças no pulso de inundação na estrutura da comunidade vegetal e na composição florística. Para Arieira e Cunha (2006), diferentes respostas das plantas às condições do hábitat mostram que algumas espécies podem servir como indicadoras de mudanças ambientais como as espécies Licania parvifolia, Combretum lanceolatum e Vochysia divergens que são indicadoras de mudanças nos ciclos de inundação ou dominância estrutural.

Conclui-se que existem diferenças florísticas e estruturais entre Cambarazal, Formação Savânica, Campo de Murundu e Formação semidecidual. Houve, também, ordenação das fisionomias de acordo com o tempo de inundação e a presença de espécies indicadoras por fitofisionomia.

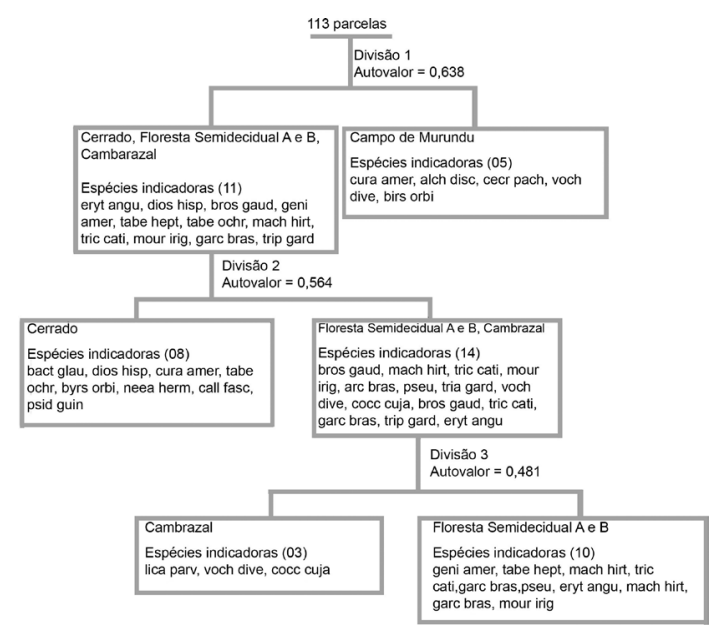

Figura 5 - Análise de TWISPAM para divisões das fitofisionomias em relação às espécies indicadoras, com base nos dados de presença e ausência no Pantanal de Poconé, Mato Grosso.

Figure 5 - TWISPAM analysis for divisions of phytophygsionomies relative to indicator species, based on presence and absence data at Pantanal of Poconé, Mato Grosso.

\section{Referências}

Abdon, M.M. \& Silva, J.S.V. 2008. Identificação de padrões em imagens Landsat-ETM+ para interpretação da vegetação arbórea do cerrado na sub-região de Cáceres, no Pantanal do Estado de Mato Grosso. In: Semana de Geografia da Unemat. Vol. 9. Universidade Estadual de Mato Grosso, Cáceres. Pp. 1-13. 
Abdon, M.M.; Silva, J.S.V.; Pott, V.J. Pott, A. \& Da Silva, M.P. 1998. Utilização de dados analógicos do Landsat - TM na discriminação da vegetação de parte da sub-região da Nhecolândia no Pantanal. Pesquisa Agropecuária Brasileira 33: 1799-1813.

Adámoli, J. 1982. O Pantanal e suas relações fitogeográficas com os cerrados: discussão sobre o conceito de complexo do Pantanal. In: Anais do $32^{\circ}$ Congresso nacional da Sociedade Botânica do Brasil, Teresina. Universidade Federal do Piauí, Teresina. Pp. 109-119.

Almeida, N.N. 2001. Mapa de vegetação e uso do solo da região de Poconé, MT: 1, descrição das unidades. In: Simpósio sobre recursos naturais e sócio econômicos do Pantanal: os desafios do novo milênio. Vol. 3. EMBRAPA. Corumbá. P. 18.

Arieira, J. \& Cunha, C.N. 2006. Fitossociologia de uma floresta inundável monodominante de Vochysia divergens Pohl (Vochysiaceae), no Pantanal Norte, MT, Brasil. Acta Botanica Brasilica 20: 569-580.

Borges, H.B.N. \& Shepherd, G.J. 2005. Flora e estrutura do estrato lenhoso numa comunidade de Cerrado em Santo Antônio de Leverger, MT, Brasil. Revista Brasileira de Botânica 28: 61-74.

Capelo, J. 2003. Conceitos e métodos da fitossociologia: formulação contemporânea e métodos numéricos de análise da vegetação. Oeiras: Estação Florestal Nacional, Sociedade Portuguesa de Ciências Florestais. 108p.

Costa, C.P.; Cunha, C.N. \& Costa, S.C. 2010. Caracterização da flora e estrutura do estrato arbustivo-arbóreo de um cerrado no Pantanal de Poconé, MT. Biota Neotropica 10: 61-73.

Cunha, C. \& Junk, W.J. 1999. Composição florística de capões e cordilheiras: localização de espécies lenhosas quanto ao gradiente de inundação no Pantanal de Poconé-MT. In: Simpósio de Recursos Naturais e Socio-Econômicos do Pantanal. Vol. 2. Corumbá. Pp. 134-148.

Cunha, C. \& Junk, W.J. 2001. Distribution of woody plant communities along the flood gradient in the Pantanal of Poconé, Mato Grosso, Brazil. International Journal of Ecology and Environmental Sciences 27: 63-70.

Custódio Filho, A. 1994. Composição florística da vegetação arbórea da floresta mesófila semidecídua da estação ecológica de Ibicatu, Piracicaba, SP. Revista do Instituto Florestal 6: 99-111.

Eiten, G. 1972. The cerrado vegetation of Brazil. Botanical Review 38: 201-341.

Felfili, J.M.; Carvalho, F.A. \& Haidar, R.F. 2005. Manual para o monitoramento de parcelas permanentes nos biomas cerrado e pantanal. Universidade de Brasília, Departamento de Engenharia Florestal, Brasília. 60p.

Felfili, J.M. 2011. Fitossociologia no Brasil: métodos e estudos de casos. UFV, Viçosa.
Fidalgo, O. \& Bononi, V.L. (coords.). 1984. Técnicas de coleta, preservação e herborização de material botânico. Manual n. 4. Instituto de Botânica, São Paulo. 61p.

Furley, P.A. 1986. Classification and distribution of murunds in the cerrado of Central Brazil. Journal of Biogeography 13: 265-268.

Gottsberger, G. \& Silberbauer-Gottsberger, I. 2006. Life in the Cerrado: a South American tropical seasonal vegetation. Vol. 1. Origin and structure, dynamics and plant use. Reta Verlag, Ulm. 280p.

Harris, M.B. 2005. Desafios para proteger o Pantanal brasileiro: ameaças e iniciativas em conservação. Megadiversidade 1: 156-164.

Junk, W.J. 1989. Flood tolerance and tree distribution in central Amazonia. In: Holm-Nielsen 1, B.; Nielsen, I.C. \& Balslev, H. (eds.). Tropical forest botanical dynamics: speciation and diversity. Academic Press, London. Pp. 47-64.

Margurran, A.E. 1988. Ecological diversity and its measurements. Croom Helm, London. 215p.

Marimon, B.S. et al. 2012. Florística dos Campos de Murundus do Pantanal do Araguaia, Mato Grosso, Brasil. Acta Botanica Brasilica 26: 181-196.

Morais, F.M.; Pereira, R.S.; Rezendez, A.V.; Nappo., M.E. \& Pinto, J.R.R. 2011. Estrutura e diversidade da vegetação arbórea-arbustiva em Cerrado sensu stricto submetido a distúrbios antrópicos. Revista Científica Eletrônica de Engenharia Florestal 18: 53-70.

Mueller-Dombois, D. \& Ellenberg, H. 1974. Aims and methods of vegetation ecology. Wiley, New York. $547 \mathrm{p}$.

Nascimento, M.T. \& Cunha, C.N. 1989. Estrutura e composição florística de um cambarazal no pantanal de Poconé - MT. Acta Botanica Brasilica 3: 3-23.

Nasser, O.S.; Cunha, C.N \& Costa, C.P. 2008. Florística de campo sujo com Vochysia divergens Pohl (Vochysiaceae) no norte do Pantanal. In: Simpósio Nacional do Cerrado. $9^{\text {a }}$ ed. EMBRAPA, ParlaMundi, Brasília. P. 8.

Oliveira-Filho, A.T. 1992. The vegetation of Brazilian 'murundus' - the island-effect on the plant community. Journal of Tropical Ecology, Cambridge 8: 465-486.

Padilha, D.R.C.; Salis, S.M. \& Crispim, S.M.A. 2008. Fitossociologia das espécies lenhosas em Campo Cerrado no Pantanal de Poconé e Paiaguás. Boletim de Pesquisa e Desenvolvimento, Corumbá. 21p.

Pott, A. \& Adámoli, J. 1999. Unidades de vegetação do Pantanal de Paiaguás. In: Simpósio sobre Recursos Naturais e Socio-Econômicos do Pantanal, Manejo e Conservação, Corumbá. Vol. 2. Embrapa, Corumbá. Pp.183-202.

Pott, A. \& Pott, V. J. 1994. Plantas do Pantanal. Embrapa, Brasília. 320p.

Pott,A. \& Pott, V.J. 2009. Vegetação do pantanal: fitogeografia e dinâmica. In: Simpósio de Geotecnologias no 
Pantanal, 2, Corumbá. Vol. 2. Embrapa Informática Agropecuária/INPE. Pp. 1065-1076.

Rebellato, L. \& Nunes da Cunha, C. 2005. Efeito do "fluxo sazonal mínimo da inundação" sobre a composição e estrutura de um campo inundável no Pantanal de Poconé, MT, Brasil. Acta Botanica Brasilica 19: 789-799.

Resende, I.L.M.; Araújo, G.M.; Oliveira, A.P.A.; Oliveira, A.P.O. \& Avila-Junior, R.S. 2004. A comunidade vegetal e as características abióticas de um campo de murundu em Uberlândia, MG. Acta Botanica Brasilica 18: 9-17.

Ribeiro, J.F. \& Walter, B.M.T. 2008. As principais fitofisionomias do Bioma Cerrado. In: Sano, S.M.; Almeida, S.P. \& Ribeiro, J.F. (eds.). Cerrado: ecologia e flora. Embrapa Cerrados, Planaltina. Pp. $151-212$

Salomão, A.K.D.; Pontara,V.; Seleme, E.P.; Bueno,M.L.; Fava, W.S.; Damasceno-Junior, G.A. \& Pott, A. 2008. Fitossociologia e florística de um trecho de mata ciliar do Rio Miranda MS, Brasil. In: Simpósio Nacional do Cerrado. $9^{\mathrm{a}}$ ed. EMBRAPA, ParlaMundi, Brasília. P. 7.

Silva, M.P.; Moura, R.; Mourão, G. \& Coutinho, M. 2000. Distribuição e quantificação de classes de vegetação do Pantanal através de levantamento aéreo. Revista Brasileira de Botânica 23: 143-152.

Souza, D.R. \& Souza, A.L. 2004. Estratificação vertical em floresta ombrófila densa de terra firme não explorada, Amazônia Oriental. Revista Árvore 28: 691-698.

Souza, V.C. \& Lorenzi, H. 2008. Botânica sistemática: guia ilustrativo para identificação de famílias fanerógamas nativas e exóticas do Brasil, baseado em APG II. 2a . ed. Instituto Plantarum, Nova Odessa. 704p.

Vilela, E.A.; Oliveira-Filho, A.T; Gavilanes, M. L. \& Carvalho, D.A. 1993. Espécies de matas ciliares com potencial para estudos de revegetação no alto Rio Grande, sul de Minas. Revista Árvore 17: 117-128. 